\title{
Safety and effectiveness of the fast-track attention model vs. conventional care in uncomplicated appendicitis of the pediatric patient
}

\author{
Seguridad y eficacia del modelo de atención fast-track vs. atención convencional en \\ apendicitis no complicada del paciente pediátrico
}

\author{
Alberto Tlacuilo-Parra ${ }^{*}$, Sandy P. López-Valenzuela², Gabriela Ambriz-González ${ }^{2}$ and Elizabeth \\ Guevara-Gutiérrez ${ }^{3}$
}

${ }^{1}$ Health Research Division, High Specialty Medical Unit (UMAE) Pediatrics Hospital, Centro Médico Nacional de Occidente, Instituto Mexicano del Seguro Social (IMSS); ' $D$ epartment of Pediatric Surgery, UMAE Pediatrics Hospital, Centro Médico Nacional de Occidente, IMSS; ${ }^{3}$ Departmeent of Dermatology, Instituto Dermatológico de Jalisco. Guadalajara, Jalisco, Mexico

\begin{abstract}
Objective: To compare safety and efficacy of fast-track program vs. conventional attention in non-complicated appendicitis attending a pediatric university hospital. Method: Randomized clinical trial, comparing two groups with 30 patients each: (A),fasttrack group, appendicitis agreeing the treatment protocol; and (B) conventional attention group, appendicitis following habitual surgical care. The efficacy and safety measures were length of hospital stay and proportion of complications. Results: We included 60 patients, there were no significant difference between groups with regard: male gender (53 vs. $60 \%$ ), age (8 $\pm \frac{5}{3}$ vs. $8 \pm 2$ years-old), time of evolution ( $23 \pm 21$ vs. $24 \pm 20 \mathrm{~h}$ ), time since admittance to emergency and beginning of surgery $\sharp(6 \pm$ 4 vs. $8 \pm 6$ h), and type of appendicitis edematous (27 vs. $24 \%$ ) or suppurate (73 vs. $76 \%$ ). Mean length of hospital stay in fast-track group was $13 \pm 5$ vs. $72 \pm 40 \mathrm{~h}$ in conventional attention $(p=0.001)$. The complications were 3 and $6 \%$, respectively $(p=1.0)$. Fast-track program diminished length of hospital stay in 2.45 days per patient, representing a mean cost saying of 6,731 Mexican pesos per day, per patient hospitalized (US\$373), without increased complications. Conclusion: Fast-frack program in children with non-complicated appendicitis is safe and effective in pediatric university hospital; there was cost minimization without carelessness of safety. This program supports clinical and economic benefits, a total saving of 403,860 Mexican pesos for the 30 patients in the fast-track group.
\end{abstract}

KEY WORDS: Appendicitis. Appendectomy. Fast-track surgery. Cost analysis. Clinical trial. Children. Diagnosis-related groü.

\section{Resumen}

Objetivo: Comparar la seguridad y la eficacia de la atención fast-track vs. atención convencional en apendicitis no complicada en un hospital pediátrico. Método: Ensayo clínico controlado, aleatorizado, con dos grupos de 30 pacientes cada unö: A) fast-track, apendicitis no complicada que cumplieron el programa; y B) atención convencional, apendicitis no complicada con atención habitual. Variables de seguridad y eficacia: proporción de complicaciones y tiempo de estancia hospitalâria. Resultados: Se incluyeron 60 pacientes, sin diferencia entre grupos: sexo masculino (53 vs. 60\%), edad ( $8 \pm 3 \mathrm{vs}$. $8 \pm 2$ años), tiempo de evolución ( $23 \pm 21$ vs. $24 \pm 20$ horas), tiempo desde ingreso a urgencias hasta inicio de cirugía (6 \pm . 4 vs. $8 \pm 6$ horas), y tipo de apendicitis edematosa (27 vs. 24\%) o supurada (73 vs. $76 \%$ ). La estancia hospitalaria promedio del grupo fast-track fue de $13 \pm 5$ vs. $72 \pm 40$ horas del grupo de atención convencional $(p=0.001)$. Hubo complicaciones el el

\author{
Correspondence: \\ *Alberto Tlacuilo-Parra \\ Monte Olimpo 1413, \\ Col Independencia, C.P.44340, \\ Guadalajara Jal. México \\ E-mail: albtlacuilo. @yahoo.com
}

Date of reception: 25-02-2018

Date of acceptance: $25-04-2018$

DOI: $10.24875 / C I R U E . M 18000062$
Cir Cir. 2018;86:36

Contents available at PubMed www.cirugiaycirujanos.com 
3 y el $6 \%$, respectivamente $(p=1.0)$. La estancia hospitalaria disminuyó 2.45 días por paciente con el protocolo fast-traek, lo que representa un ahorro de \$6,731 pesos/día/paciente/hospitalización (US\$373), sin un aumento de las complicaciones. Conclusión: El protocolo fast-track en los niños con apendicitis no complicada es seguro y efectivo en un hospital universitario. El programa fast-track aportó beneficios clínicos y económicos, ahorrando en total $\$ 403,860$ en los 30 pacientes.

PALABRAS CLAVE: Apendicitis. Apendicectomía. Cirugía fast-track. Análisis de costos. Ensayo clínico. Niños. Grupós relacionados por el diagnóstico.

\section{Introduction}

Acute appendicitis is the most common surgical disease in surgery departments and is the leading acute abdomen surgical intervention that is performed in these departments worldwide'.

Fast-track surgery was established by Danish surgeon Henrik Kehlet with the purpose to optimize perioperative care in elective surgery ${ }^{2,3}$. Fast-track care comprises a comprehensive program to reduce stress and discomfort by means of preoperative instructions, mobilization and immediate postoperative nutrition, preference for minimally-invasive techniques, as well as pain treatment, avoiding on the other hand drains, tubes and catheters 4 . Fast-track surgery initial studies in pediatrics have focused on elective procedures such as appendectomy ${ }^{5,6}$, pyelotomy and pyeloplasty ${ }^{7,8}$, and nephrectomy $\mathrm{y}^{9,10}$.

According to the evidence on the feasibility of implementing the fast-track model of care even in institutions with no previous experience therewith ${ }^{11}$, and given that in our setting $47 \%$ of appendicitis surgeries correspond to uncomplicated forms (edematous and suppurated $)^{12}$, we consider it useful to compare the safety and efficacy of the fast-track care protocol vs. conventional care in children with uncomplicated appendicitis in a university pediatric hospital.

\section{Method}

Randomized, controlled clinical trial, carried out from July to December 2015 at the High Specialty Medical Unit (UMAE - Unidad Médica de Alta Especialidad) Pediatric Hospital of the National Medical Center of the West, which belongs to the Mexican Institute Social Security (IMSS - Instituto Mexicano del Seguro Social). The sample was calculated based on obtaining a difference of at least 48 hours between hospital stay means between the fast-track group and the conventional care group, with a total of 30 study subjects per group, assigned by simple randomization using a random number table. The study variables were the following: age, gender, admission shift, referral to the hospital, evolution time, time elapsed until surgery was started, hospital length of stay surgical complications, associated comorbid conditions and reason for discharge. Patients between 3 and 15 years of age treated at the emergency department with a clinical diagnosis of uncomplicated appendicitis, corroborated during surgery and operated with open appendectomy, were included.

\section{Fast-track protocol and conventional care}

A case report form was used to record the demographic characteristics, quantifying the time elapsed from hospital admission to the moment of surgery. A prophylactic antibiotic regimen was applied at the moment of anesthetic induction: cefazolin $(30 \mathrm{mg} / \mathrm{kg}$ single intravenous dose) plus metronidazole (30 mg/ $/ \mathrm{kg}$ for 5 days); in case of hypersensitivity to cephalosporins, amikacin was used ( $15 \mathrm{mg} / \mathrm{kg}$ for 3 days). Atthe time of discharge from the operating room, the parent or legal guardian was interviewed; he/she was briefed pom the purpose of the study, and after signing the informed consent, the patient was randomized to the fast-track care protocol: analgesia with paracetamol $(15 \mathrm{mg} / \mathrm{kg}$ orally every 6 hours, up to $3 \mathrm{~g} / \mathrm{day})$ for 3 days, early mobilization out of bed and early postoperative nutrition (6 hours after surgery, the oral route was initiated according to the following parämeters: no presence of vomit, no abdominal distension or pain, presence of peristalsis, with passing of gas or regular bowel movements); or to receive conventional care (as clinically judged by the pediatric surgeon responsible for the care of the patient). Ihe corresponding indications were followed according to the assigned care protocol. The hours of hospital stay were quantified from the beginning of surgery to discharge, with any complication developing during hospitalization, and the reasons for hospital discharge being documented. Within the fast-track protocol, 5 patients had to have the following discharge criteria: afebrile, presence of peristaltic noises or passing of gases, tolerance to liquids, and no nausea or vomiting. Seven days after surgery, a phone call was made 
Table 1. Comparison between the fast-track care model and conventional care

\begin{tabular}{|c|c|c|c|}
\hline & \multicolumn{2}{|c|}{$(\mathrm{N}=30)$} & \multirow[t]{2}{*}{$p$} \\
\hline & $\begin{array}{l}\text { Fast-track } \\
\text { care }\end{array}$ & $\begin{array}{l}\text { Conventional } \\
\text { care }\end{array}$ & \\
\hline Age (years) & $8 \pm 3$ & $8 \pm 2$ & $8 \pm 2$ \\
\hline Male gender & $16(53 \%)$ & $18(60 \%)$ & $18(60 \%)$ \\
\hline $\begin{array}{l}\text { Admission shift } \\
\text { Morning } \\
\text { Afternoon } \\
\text { Night } \\
\text { Shift overlap }\end{array}$ & $\begin{array}{c}2(7 \%) \\
4(13 \%) \\
16(53 \%) \\
8(27 \%)\end{array}$ & $\begin{array}{c}1(3 \%) \\
3(10 \%) \\
18(60 \%) \\
8(27 \%)\end{array}$ & 0.897 \\
\hline $\begin{array}{l}\text { Referred to the } \\
\text { hospital }\end{array}$ & $26(87 \%)$ & $27(90 \%)$ & 1.00 \\
\hline $\begin{array}{l}\text { Plain X-ray } \\
\text { diagnostic modality }\end{array}$ & $27(90 \%)$ & $27(90 \%)$ & 1.00 \\
\hline $\begin{array}{l}\text { Evolution } \\
\text { time (hours) }\end{array}$ & $23 \pm 21$ & $24 \pm 20$ & 0.71 \\
\hline $\begin{array}{l}\text { Time to initiation of } \\
\text { surgery (hours) }\end{array}$ & $6 \pm 4$ & $8 \pm 6$ & 0.104 \\
\hline Hospital stay (hours) & $13 \pm 5$ & $72 \pm 40$ & 0.0001 \\
\hline $\begin{array}{l}\text { Surgical } \\
\text { complications }\end{array}$ & $1(3 \%)$ & $2(6 \%)$ & 1.0 \\
\hline Comorbid conditions & 0 & 0 & 1.0 \\
\hline $\begin{array}{l}\text { Improvement as } \\
\text { reason for discharge }\end{array}$ & $30(100 \%)$ & $30(100 \%)$ & 1.0 \\
\hline
\end{tabular}

to both groups to determine if there were complications (hospital readmission or reoperation).

\section{Diagnosis-related groups}

Diagnosis-related Groups (DRGs) is a system for classifying and grouping hospitalized patients' clinical and surgical diagnoses and to define the level of complexity involving the care of a patient. Each DRG is constructed according to discharge diagnoses, combining different clinical features (classified by ICD-10 codes) and the surgical procedures performed (ICD9MC codes), and predominantly include consumption of resources. Appendectomy was classified, according to IMSS DRGs, within six existing categories: DRG 338, appendectomy with complicated main diagnosis, with major clinical complications; DRG 339, appendectomy with complicated main diagnosis, with clinical complications; GRD 340, appendectomy with complicated main diagnosis, with no clinical complications or major clinical complications; DRG 341, appendectomy without complicated main diagnosis, with major clinical complications; DRG 342, appendectomy without complicated main diagnosis, with clinical complications; and DRG 343, appendectomy without complicated main diagnosis, without clinical complications or major clinical complications ${ }^{13}$.

\section{Statistical analyses}

Descriptive statistics were used: averages, standard deviations and proportions. For inferential statistics, the $\chi^{2}$ test or Fisher's exact test were used to compare proportions, and Student's t-test was used to compare quantitative variables between groups. Differencewas considered to be statistically significant when $p<0.05$. A cost-minimization-type economic evaluation. Was performed for both care models regarding the hours of actual hospital stay; this analysis assumes the assessment of at least two strategies in a same disease where the responses obtained in terms of health are equal, but the cost is different. To calculate the cost of hospital stay, the unit cost tabulator by medical care level for the 2015 IMSS tax year, published in the Official Journal of the Federation, was employed ${ }^{4}$. According to this tabulator, the cost per inpatient day in tertiary care units is $\$ 6,731$ Mexican pesos. This work was approved by the Local Committee of Research and Research Ethics (R-2015-1302-34) of the UMAE Pediatrics Hospital.

\section{Results}

\section{Fast-track care group sociodemographic characteristics}

Thirty pediatric patients diagnosed with uncomplicated appendicitis, looked after for a period 6 months, were included. Comparative demographic data ${ }_{0}$ etween groups are shown in table 1. Appendicitis fype distribution, classified at surgery, was edematoús in 8 cases (27\%) and suppurative in 22 cases (73\%), which was corroborated by histopathological examination. With regard to the use of antibiotic, it was preoperatively administered in 28 cases (93\%), white in the remaining two it was intraoperatively administered (7\%). Average hospital length of stay was $13 \frac{0}{ \pm} 5$ hours. Surgical complications occurred in one case (3\%), which corresponded to a seroma that was resolved by aspiration. None of the patients had any associated comorbid condition. All 30 patients (100\%) were discharged due improvement, and during the follow-up call 7 days after hospital discharge, to 
confirm patient safety, in no case was the need for hospital readmission referred and the return of the patient to daily activities was confirmed.

\section{Conventional care group sociodemographic characteristics}

Thirty patients with an uncomplicated appendicitis diagnosis were included. The type of appendicitis distribution, classified at surgery, was edematous in 7 cases (24\%) and suppurative in $23(76 \%)$. Regarding the use of antibiotic, it was preoperatively administered in 29 cases $(96 \%)$, whereas in the rest it was intraoperatively administered (4\%). Average hospital length of stay was $72 \pm 40$ hours. There were surgical complications in two cases (6\%), which corresponded to seromas that were resolved by aspiration. None of the patients had any associated comorbid condition. All the children (100\%) were discharged due improvement, and during the follow-up call 7 days after hospital discharge, in no case was the need for hospital readmission referred and return to everyday activities was confirmed.

\section{Comparison between models of care}

There was no statistically significant difference regarding appendicitis classification between groups. Most patients were referred from other hospital units, and $50 \%$ were admitted during the night shift. The most useful imaging modality to establish the diagnosis was plain abdominal X-ray in $90 \%$ of cases. There was no difference between groups with regard to average evolution time from the onset of symptoms until they were admitted to a hospital unit, or in time elapsed in hours since admission into our unit and initiation of surgery. Average hospital length of stay in the fast-track group was $13 \pm 5$ hours, while in the conventional care group it was $72 \pm 40$ hours $(p=0.0001)$. There was no difference in the proportion of surgical complications, readmissions or comorbid conditions between the models of care. All patients were discharged due improvement and all resumed their daily activities without developing sequels

\section{Appendicitis classification by DRG and cost-minimization}

GRD 343, appendectomy without complicated main diagnosis, without major complications or comorbidity, comprised 29 patients $(97 \%)$ of the fast-track group and $28(94 \%)$ of the conventional care model. GRD 342 , appendectomy without complicated main diağhosis, with clinical complications, corresponded to $\widetilde{\theta}$ ne $(3 \%)$ and two patients (6\%), respectively.

In the fast-track group, average hospital length of stay was $13 \pm 5$ hours vs. $72 \pm 40$ hours in the eonventional care model group, with a difference between groups of 59 hours (2.45 days), which translates in to a cost reduction of at least $\$ 13,462$ Mexican pesos (considering only 2 days and eliminating the fraction of remaining hours) per patient treated with open appendectomy within the fast-track care model.

\section{Discussion}

The application of the fast-track model to emergency surgical interventions appears to be contributing good results in those pathologies that have no serious complications. In these cases, action on the preoperative phase becomes more difficult, since the time between diagnosis and surgical interventionencompasses barely a few hours, and patient clinical situation entails, in most cases, inadequate nutritiōnal and metabolic control ${ }^{15}$. Thus, intraoperative and postoperative stages acquire more relevance. However, prior to emergency surgical intervention, the information and education protocol should be initiated, incaddition to antibiotic prophylaxis and hydroelectrolytic resuscitation, trying to bring the patient to surgery with an adequate fluid balance that ensures tissue perfusion without causing edema ${ }^{16,17}$.

Acute appendicitis is the most common surgical emergency pathology in the child, but there is nofyet a consensus regarding its therapeutic management. In the literature, there are several studies on the treatment of pediatric-age acute uncomplicated appendicitis using rapid pathways. With these approackes, rapid postoperative recovery is achieved, resembling the times of scheduled surgical intervention fast-track protocols. Two key pieces for their success are the use of the laparoscopic route as surgical technique, especially in selected cases (pubertal girls and obese patients), and prophylactic antibiotic dosage implementation ${ }^{18,19}$. Another cardinal point in the fast-tiack care model is avoiding peritoneal drains in order to prevent the formation of abscesses, as well as avoiding the placement of a nasogastric tube to prevent abdominal distension and vomiting, because, currently, these last two actions are claimed to have noadvantages versus not carrying them out, and they can 
even increase the presence of complications ${ }^{20,21}$. Early oral tolerance improves patient comfort and decreases hospital length of stay ${ }^{22}$. In addition, there are works that support early postoperative tolerance in cases of complicated acute appendicitis in order to reduce paralytic ileus ${ }^{15}$.

The application of a fast-track care model in acute uncomplicated appendicitis within the setting of a university hospital is feasible and useful when compared to the conventional care model, and it translates into the following clinical benefits: a) a decrease in hospital length of stay of 2.4 days, which means a reduction in anxiety and stress for both the patient and the family and a quick reintegration to usual family dynamics; b) quality of care, since the call made to the patients 7 days after the intervention, with the purpose to verify the safety of the procedure and avoid complications or readmissions, was perceived as an improvement in the quality of the provided care; and $c$ ) reduction in the risk for developing nosocomial infection. Moreover, it also translates into economic benefits, which are reflected on a decrease in hospital stay of more than 2 days per patient, which entails an average saving of $\$ 13,462$ pesos per hospitalized patient. If we consider that, according to a previous publication of our group ${ }^{12}, 47 \%$ of pediatric patients with appendicitis have uncomplicated forms, and that, during 2014, 386 appendectomies were carried out at the unit, 185 of them would correspond to uncomplicated forms, which would represent a total saving of $\$ 2,490,470$ pesos, with no detriment of patient safety.

Our study has limitations that we should recognize. The sample size is small, given that it is a pilot study whose purpose was to determine the feasibility of establishing a fast-track model of care in the setting of a university hospital. In addition, the therapeutic protocol was restricted to the role of the surgeon, and mainly to his/her performance in the postoperative phase, without considering the role of the anesthesiologist and, therefore, the fast-track model concept is incomplete.

\section{Conflicts of interests}

None to declare.

\section{References}

1. Humes DJ, Simpson J. Acute appendicitis. BMJ. 2006;335:530-4

2. Kehlet $\mathrm{H}$. Effect of postoperative pain treatment and outcome-current status and future strategies. Langenbecks Arch Surg. 2004;389:244-9.

3. Wilmore DW, Kehlet $\mathrm{H}$. Management of patients in fast-track surgery. BMJ. 2001;322:473-6.

4. Reismann M, Arar M, Hofmann A, Schukfeh N, Ure B. Feasibility offasttrack elements in pediatric surgery. Eur J Ped Surg. 2012;22:40-4.

5. Grewal H, Sweat J, Vázquez WD. Laparoscopic appendectomy iß̧children can be done as fast-track or same day surgery. J Soc Laparoendosc Surg. 2004:8:151-4.

6. Serour F, Witzling M, Gorenstein A. Is laparoscopic appendectomy in children associated with an uncommon postoperative complication? Surg Endosc. 2005;19:919-22.

7. Mohamed M, Hollins G, Eissa M. Experience in performing pyelolithotomy and pyeloplasty in children on day surgery basis. Urology. 2004;64:1220-2.

8. Metzelder ML, Schier F, Petersen C. Laparoscopic trans-abdominalpyeloplasty in children is feasible irrespective of age. J Urol. 2006;175:688-91.

9. Mulholland TL, Kropp BP, Wong C. Laparoscopic renal surgery in ihfants $10 \mathrm{~kg}$ or less. J Endourol. 2005;19:397-400.

10. Jesch NK, Metzelder ML, Kuebler JF. Laparoscopic trans-peritoneal nephrectomy is feasible in the first year of life and is not afected by kidney size. J Urol. 2006;176:1177-9.

11. Schukfeh N, Reismann M, Ludwikowski B, Hofmann AD, Metzelder ML, Ure B. Implementation of fast-track pediatric surgery in a German nonacademic institution without previous fast-track experience. Eur J Pediatr Surg. 2014;24:419-25.

12. Tlacuilo-Parra $A$, Hernández-Hernández $A$, Venegas-Dávalos $M$, Gutiérrez-Hermosillo V, Guevara-Gutiérrez E, Ambriz-González G. Costos de tratamiento de la apendicitis mediante grupos relacionados con eldiagnóstico en un tercer nivel de atención pediátrica. Cir Cir. 2014;82:628-36.

13. Arroyave LMG, Aburto MR, Dávila TJ, editores. Enfermedades y trastornos del sistema digestivo. En: Grupos relacionados con el diagnóstico: producto hospitalario. GRD-IMSS: 2012. México, DF: Instituto Mexicano del Seguro Social; 2014. p. 57-70.

14. Diario Oficial de la Federación. Acuerdo ACDO.AS3.HCT.280115/7.P.DF y sus Anexos, dictado por el H. Consejo Técnico, celebrado el 28 de enero de 2015, relativo a la aprobación de los Costos Unitarios poéNivel de Atención Médica para el ejercicio 2015 del IMSS. Diario Oficial, miércoles 11 de febrero de 2015 .

15. Lasso B, Ruiz H, Vargas V. Aplicación de un modelo terapéutico fasttrack en la apendicitis aguda complicada del paciente pediátrico. Cir Pediatr. 2013;26:63-8.

16. Holte $\mathrm{K}$, Kehlet $\mathrm{H}$. Fluid therapy and surgical outcomes in elective- surgery: a need for reassessment in fast-track surgery. J Am Coll Surg. 2006:202:971-89.

17. Tuduri L, Morcillo A, Granero C. Protocolo antibiotico "fast-track" en la apendicitis aguda. Cir Pediatr. 2009;22:142-4.

18. Wojciech J, Gronchowski JA. Are antibiotics necessary in nonperforated appendicitis in children? A doble blind randomized controlled tria 5 Med Sci Monit. 2001;7:289-92.

19. Reissman M, Kampen M, Laupichler B. Fast-track surgery in infants and children. J Pediatr Surg. 2007:42:234-8.

20. Perovic Z. Drainage of the abdominal cavity and complications in perforating appendicitis in children. Med Pregl. 2000;53:193-6.

21. Jottard K, Hoff C, Maessen J. Life and death of nasogastric tube in elective colonic surgery in the Netherlands. Clin Nutr. 2009;28:26-8.

22. Chopra S, Schmidt SC, Fotopoulou C. Evidence-based perioperative management: strategic shitfs in times of fast track surgery. Anticancer Res. 2009;29:2799-802. 